\title{
Martba Santillán
}

Doctoranda en Historia por la Universidad Nacional Autónoma de México (UNAM) y maestría en Estudios Latinoamericanos por la misma universidad. Actualmente dirige el seminario de titulación en la maestría en Historia de México del Instituto Cultural Helénico; se ha desempeñado como profesora en las Universidades Iberoamericana y Anáhuac. Sus temas de interés son la historia cultural con énfasis en estudios de género y de mujeres en el siglo XX. Ha sido ponente en congresos nacionales e internacionales. Su más reciente publicación es "Discursos de redomesticación femenina durante los procesos modernizadores en México, 1946-1958", Historia y Grafía, Universidad Iberoamericana, núm. 31, diciembre de 2008.

\section{Resumen}

En el presente artículo se analizan las contribuciones del periódico Excélsior en la construcción de la imagen femenina como sujeto doméstico, en el contexto del gobierno conservador de Manuel Ávila Camacho (1940-1946), a través de la creación de diversos concursos en torno a la maternidad, entre los que destacó de manera especial el de "las madres prolíficas". En este periodo, las elites dirigentes se dieron a la tarea de establecer el papel ideal femenino vinculado a la maternidad, mediante el cual pretendían controlar el acceso de las mujeres a los diversos espacios públicos y acotar su campo de acción a la vida del hogar. En este sentido el diario sirvió como instrumento ideologizante para promover el rumbo que tomarían las políticas de género de los gobiernos en México a partir de la década de los cuarenta. A través del presente estudio sobre la prensa, podemos constatar que existió un expreso interés por parte de los grupos hegemónicos por limitar en los planos ideológicos y culturales la realización de las mexicanas al ámbito doméstico, y consolidar como eje constituyente de la identidad nacional, la idea de la familia tradicional.

Palabras clave:

Discurso, maternidad, prensa, género, Manuel Ávila Camacho, ideología conservadora, México. 


\title{
Traditionalist Discourse on Motherhood: Excélsior and Prolific Mothers during Ávila Camacho's Administration
}

\author{
Martha Santillán
}

Doctoral candidate in History at the National University of Mexico (UNAM), M. A. in Latin American Studies at UNAM. Currently the director of the Seminar on the Completion of M. A. degrees in Mexican History at the Instituto Cultural Hellénico, she has taught at the Universidad Iberoamericana and the Universidad Anáhuac. Her areas of interest are cultural history, with an emphasis on gender and women's studies in the 20th century. She has delivered papers at national and international congresses. Her most recent publication is "Discursos de redomesticación femenina durante los procesos modernizadores en México, 1946-1958", Historia y Grafía, Universidad Iberoamericana, no. 31, December 2008.

\begin{abstract}
This article analyzes the contributions of Excelsior newspaper to the construction of the female image as a domestic subject within the context of the conservative government of Manuel Ávila Camacho (1940-1946) through the creation of various competitions regarding motherhood, particularly the one on "prolific mothers." During this period, the ruling elites set about establishing the ideal female role linked to motherhood, through which they sought to control women's access to various public spaces and

limit their sphere of action to the home. In this respect, the newspaper served as an ideologizing instrument to promote the path that Mexican government's gender policies would take from the 1940s onwards. This study on the press shows that there was an express interest by hegemonic groups in restricting Mexican women's fulfillment at the ideological and cultural level to the domestic sphere and in consolidating the idea of the traditional family as the axis of national identity.
\end{abstract}

Key words:

Discourse, Motherhood, Press, Gender, Manuel Ávila Camacho, Conservative Ideology, México.

Final submission: 


\title{
El discurso tradicionalista sobre la maternidad: Excélsior y las madres prolíficas durante el avilacamachismo*
}

\author{
Martha Santillán
}

$\mathrm{E}$ n los años cuarenta comenzó en México una época de bonanza ecoel gobienica y de estabilíad social. Con el gobierno de Manuel Ávila Camacho (1940-1946) se modificó el rumbo del "socialismo mexicano" instrumentado por el presidente Lázaro Cárdenas (1934-1940) hacia un "sistema más acorde con el capitalismo ortodoxo", ${ }^{1}$ mientras que en los ámbitos de la educación y la moral se retomó el curso del conservadurismo. En el plano internacional, la coyuntura de la segunda guerra mundial ayudó a que se limaran las asperezas con Estados Unidos: se liquidaron los recientes conflictos consecuencia de la expropiación petrolera (1938) y se firmó un acuerdo de cooperación mutua que posibilitó a México acceder a sistemas de crédito estadunidense que permitieron estimular la industrialización y, con ello, la modernización de la nación. Asimismo, el conflicto bélico mundial sirvió al presidente para convo-

* Agradezco a la doctora Carmen Ramos Escandón por compartir conmigo sus conocimientos sobre el estudio de las mujeres, que han resultado valiosas herramientas para el desarrollo de mi trabajo, así como las conversaciones respecto al tema de este artículo que me ayudaron en el proceso de reflexión.

${ }^{1}$ Meyer, "Institucionalización", 2000, p. 826. car a la "unidad nacional"; lema que, a su vez, operó como una estrategia discursiva para homogeneizar las divergencias sociales, políticas e ideológicas existentes en el país. En este escenario, las elites también se dieron a la labor de establecer el papel ideal, acorde con las nuevas circunstancias de la nación, para las mujeres mexicanas; tal como sucedió con el concurso "madres prolíficas" promovido por el diario Excélsior.

La desestabilización social producida por la revolución mexicana y los conflictos sociales de las décadas de los veinte y treinta habían permitido que las mujeres tuvieran una participación más notoria en actividades políticas, laborales y culturales fuera del espacio doméstico. ${ }^{2}$ Los cambios habían comenzado a constatarse desde la Convención Revolucionaria de 1914-1916, en la cual se aprobó la investigación de la paternidad con el fin de proteger a las mujeres de los varones que las abandonaban evadiendo la responsabilidad con los

${ }^{2}$ Existen diversos estudios sobre mujeres en México, en los que se abordan los avances femeninos en el siglo Xx. Vale la pena destacar los trabajos de Blanco, Mujeres, 2001; Herrera, Estudios, 2006; Lamas, Miradas, 2007, y Tuñón, Fin, 2000, y Mujeres, 2004. 
hijos. Venustiano Carranza otorgó pensiones para aquellas que habían combatido en la guerra revolucionaria y apoyó los congresos feministas de Yucatán (1916), en los cuales se proponía que se ofreciera una formación laica y anticlerical para las escolares así como la posibilidad de brindarles educación sexual; se planteó la importancia de enseñarles actividades, ciencias y artes que les permitieran desarrollarse laboralmente, y también se pedía que las mujeres pudieran asumir cargos públicos. En 1917 se expidió la Ley de Relaciones Familiares que establecía la igualdad entre los cónyuges, quienes debían decidir en común acuerdo la educación de los hijos y la administración de los bienes familiares; asimismo, se reconocieron los derechos de las casadas a disponer de sus bienes y se legalizó el divorcio. ${ }^{3}$

A partir de entonces y durante las dos siguientes décadas, la negociación entre las elites políticas y los movimientos feministas más organizados fue ardua ya que los grupos de poder político, en general, no mostraban simpatía respecto a una abierta integración femenina a la vida pública. ${ }^{4}$ Sin embargo, al llegar la década de los cuarenta, el ambiente de conservadurismo promovido por el avilacamachismo permitió que se fueran ignorando las demandas de grupos femeninos que habían estado propugnando por una mejor situación social para las mexicanas; sus peticiones fueron canibalizadas silenciosamente por una serie de discursos que fortalecían los valores decimonónicos referentes a la feminidad vinculada a la maternidad.

\footnotetext{
${ }^{3}$ Cano, "Revolución", 2000, pp. 751-752.

${ }^{4}$ Ramos, "Participación", 1994, pp. 186-172.
}

En este contexto, el periódico derechista Excélsior, conocido como el Diario de la Vida Nacional y suscrito a la línea oficial gubernamental, se posicionó como un actor fundamental al convertirse en intermediario y promotor de la idea de la madre como agente de amor, gozo, sufrimiento y resignación, cualidades inherentes a la supuesta naturaleza femenina. Así, en 1941 este rotativo externaba sus loas a la maternidad al festejar a la mujer que tuviera el mayor número de hijos a través de un concurso llamado "la madre prolífica", excluyendo de esta manera las voces de los grupos sociales que aún luchaban por la obtención del voto y otros derechos sociales para las mexicanas.

El presente trabajo pretende mostrar, por un lado, la contribución de este periódico a la construcción de una imagen femenina absolutamente doméstica, así como su nexo ideológico con la elite gobernante y otros grupos conservadores preocupados por las conductas de la "mujer moderna" en medio de cambios políticos, económicos y sociales que remodelaban las posibilidades de desarrollo para las mexicanas. Planteamos que dicha postura, frente a la inminente $-y$ necesaria- modernización del país, intentaba acotar primordialmente los comportamientos femeninos a la regencia del hogar más que a alentar su desempeño en los espacios públicos. En este sentido, buscamos bosquejar una faceta de la visión oficialista con respecto a la feminidad implementada en los primeros años de la década de los cuarenta, periodo donde las transformaciones sociales eran cada vez más notorias y comenzaban a afectar a sectores más amplios de la población femenina. 
LA NUEVA MORAL CONSERVADORA Y LA PRENSA

Manuel Ávila Camacho asumió la presidencia de la república el 1 de diciembre de 1940. En el ámbito interno, las elecciones sangrientas y dudosas que lo llevaron al poder evidenciaban que el país estaba aún fuertemente dividido por las antagónicas tendencias políticas e ideológicas del socialismo impulsado durante el sexenio cardenista y una derecha extremadamente conservadora. En el ámbito externo, debió enfrentar los saldos de la expropiación petrolera y negociar con las diversas fuerzas políticas y una parte considerable de la opinión pública, la colaboración militar de México con Estados Unidos y la incursión del país en la guerra europea. ${ }^{5}$

A través del lema "Unidad nacional" el presidente pretendía, por un lado, unir a un país dividido por cuestiones políticas, ideológicas, económicas y sociales y, por otro, que tanto la opinión pública como representantes populares -diputados y senadores- se solidarizaran con el gobierno frente a la situación de guerra en que México se veía cada vez más inmiscuido. Asimismo, dicho emblema serviría a su gobierno para apelar al sentimiento nacionalista con la finalidad de aglutinar los intereses necesarios para impulsar la sus-

${ }^{5}$ Los acuerdos referentes a la deuda petrolera se firmaron en noviembre de 1941; en ellos se establecía la creación de una comisión conjunta para evaluar los bienes expropiados -excluyendo el petróleo del subsuelo- y definir la forma de pago. En cuanto a la cooperación militar entre ambas naciones, estas comenzaron a tomar dirección en enero de 1942 y un rumbo definitivo con la declaración del "estado de guerra" el 22 de mayo de ese mismo año. Véase Torres, Historia, 2005, pp. 65-150. titución de importaciones por medio de la industrialización. En su toma de protesta como presidente, el nuevo mandatario aseguraba que la

república entera demanda la consolidación material y espiritual de nuestras conquistas sociales en una economía próspera y poderosa. Demanda una era de construcción, de vida abundante, de expansión económica. ${ }^{6}$

Ávila Camacho estaba convencido de que esta sería la vía para encarrilar al país en el sendero del progreso.

En este contexto, la relación entre la prensa y el gobierno se vio fortalecida por diversos factores económicos y políticos. A raíz del conflicto bélico europeo, Estados Unidos mostró un marcado interés en que los periódicos mexicanos difundieran una imagen que aminorara el generalizado sentimiento antiestadunidense $y$, asimismo, en que apoyasen las políticas del gobierno avilacamachista en aras de la colaboración militar entre ambas naciones. En tanto, los dirigentes de los diarios más importantes de México como Excélsior (Rodrigo de Llano), El Universal (Miguel Lanz Duret), Novedades (Ignacio Herrerías) y La Prensa (Luis Novaro), ante el temor de no contar con herramientas necesarias para su producción (en especial el papel que se importaba de Europa), solicitaron en abril de 1941 apoyo económico al gobierno estadunidense para construir una fábrica de papel y para el suministro de refacciones y equipo para sus instalaciones. Para evitar cualquier crítica en México los directivos pidieron que no quedara constancia de su solicitud y que el préstamo (entre 500000 y 6000000 de dóla-

${ }^{6}$ Los presidentes, 1966, p. 149. 
res) se hiciera a través de un banco privado. $Y$, aunque no hay registro de que se haya efectuado dicho financiamiento, como asegura Blanca Torres, lo cierto es que en Estados Unidos imperaba la disconformidad de los diarios locales porque aducían que se les racionaba el papel en tanto que a los periódicos mexicanos se les abastecía sin mayor restricción. ${ }^{7}$ De cualquier manera, es un hecho que la prensa mexicana se esforzó por mostrar una mejor imagen del país vecino en tanto se daba a la tarea de promover un discurso favorable al gobierno de Ávila Camacho.

Tras la declaración del estado de gue$\mathrm{rra}^{8}$ en México se suspendieron diversas garantías constitucionales, entre ellas la libertad de prensa (consignada en el artículo séptimo) $)^{9}$ ya que se argumentaba que era necesario controlar la divulgación de información alienígena que pudiera alterar el orden interno. La prensa, por su parte, no dio más que muestras de apoyo al gobierno ante la contingencia de la guerra, mientras que en el plano ideológico y moral también empatizaron con

${ }^{7}$ Para más detalles sobre estas negociaciones, véase Torres, Historia, 2005, pp. 99-100.

${ }^{8}$ Después de un sinuoso ir y venir entre la presión estadunidense y el rechazo mayoritario de grupos políticos y sociales frente a la participación de México en una guerra considerada lejana y un antiyanquismo extendido que repudiaba la colaboración con los Estados Unidos, la creación del "estado de guerra" fue la salida del gobierno avilacamachista. Este se concibió "como la guerra con todas sus consecuencias pero a la defensiva; no comprometía a pagar cuota de sangre en el conflicto, cuando mucho una cuota económica". Así, México justificaba su colaboración con Estados Unidos en el bando de los países aliados dentro del conflicto europeo sin generar mayores contrariedades. Ibid., p. 94.

${ }^{9}$ Ibid., pp. 94-95, n. 61. el tradicionalismo del régimen avilacamachista.

Por su parte, los sectores conservadores que desconfiaban de las políticas socialistas de la administración cardenista, encontraron en el nuevo presidente un aliado, sobre todo tras haberse declarado católico creyente. ${ }^{10}$ Así, se implementaba una política de conciliación con la Iglesia católica, que cimentó una atmósfera de conservadurismo y de reedificación de los valores tradicionales que promovían a las familias numerosas como base de la sociedad. En este marco, la política de unidad nacional abarcaba, a decir de Martha Eva Rocha, la defensa de la familia y de la mujer como eje del hogar. ${ }^{11}$ Desde su campaña presidencial, el sucesor de Cárdenas consignó su postura frente a la maternidad en lo que Excélsior tituló "Bello elogio a la madre":

La madre mexicana, la madre humilde del pueblo, vive frecuentemente entre nosotros sometida a los más duros abandonos, a las más tristes condiciones $[. .$.$] una civilización$ se caracteriza por la protección que la comunidad extiende sobre los seres débiles, y la

${ }^{10}$ De acuerdo con José Agustín, ello provocó que el futuro presidente recibiera el mote de "Ávila Camocho". José Agustín, Tragicomedia, 2007, p. 19. Véase también el video documental de Krauze y Lupone, Manuel, 1998, min. 5.

${ }^{11}$ Rocha, "Mexicanas", 2001, pp. 124-125. Si bien desde el porfiriato se había procurado consolidar el papel femenino dentro del hogar, para el siglo Xx las políticas estatales de protección a la familia tenían que enfrentar una serie de cambios sociales que posibilitaban la realización de la mujer en espacios distintos a los domésticos. En este sentido, para el Estado posrevolucionario la familia constituyó un puntal fundamental de la estructura social que debía fortalecerse. 
mujer es la medida de esa debilidad. Sobre todo la mujer en su misión de maternidad y educación de la raza en un estado bien organizado, una mujer en camino a ser madre y en el desempeño de sus funciones maternales, no debe estar tan desamparada. [...Por ello se comprometía a] organizar una campaña de veneración, de respeto a la madre. ${ }^{12}$

El próximo líder de la nación evidenciaba en este discurso una preocupación por la situación de las mujeres, a las cuales asumía como intrínsecamente débiles y con el cometido natural de ser madres y, por ello, víctimas de terribles abandonos y desamparos. Esta postura se contraponía, sin duda, a los planteamientos de los sectores progresistas referentes a la adquisición de derechos y a la conformación de otros espacios de participación social para las mujeres. Asimismo muestra que el Estado posrevolucionario se planteaba la posibilidad de otorgar al sexo femenino una mejor situación social, sólo que a través de su expresa protección y ayuda para que cumplieran su cara misión de madres. De esta suerte, Ávila Camacho dejaba claro cuál debía ser el papel de las mexicanas durante la nueva época que vivía el país: estar al margen de los acontecimientos públicos y abocarse preferentemente a la procreación y el cuidado del hogar.

Ese estereotipo también era avalado por el catolicismo que enaltecía a la Virgen María, arquetipo de la madre perfecta. ${ }^{13}$ De hecho, para hacer frente a la devastación del mundo moderno, el papa Pío XII

12 "Bello elogio a la madre", Excélsior, 12 de mayo de 1940, México, 1a. secc., pp. 1, 14.

${ }^{13}$ Para un análisis más detallado del vínculo de la maternidad y la virgen de Guadalupe, véanse Torres, "Familia", 2006, y Aspe, Formación, 2008. aseguró, en un discurso dirigido a la Acción Católica en 1940, que las mujeres eran responsables de restituir el matrimonio, de renovar el ámbito familiar y de difundir la forma de vida católica en los hogares. ${ }^{14}$ Para este sector religioso, las jóvenes no debían fijarse en aquellas propuestas que desviaran sus intereses por formar y consolidar una familia católica; es decir, su única circunstancia de vida debía ser el matrimonio y garantizar la transmisión de la fe.

Diversos grupos conservadores aprovecharon el giro en las políticas del nuevo régimen gubernamental para evidenciar sus latentes preocupaciones ante la intromisión de estilos ajenos a las formas de vida nacionales, sobre todo en el ámbito familiar; en otras palabras, ante la posibilidad de que las mujeres adquiriesen una responsabilidad (trabajo o educación) adicional a la doméstica. Por ejemplo, para el reconocido politólogo de la época José E. Iturriaga el hecho de que ellas trabajaran les otorgaba una actitud de autosuficiencia económica que confería "al matrimonio una estabilidad menor, pues como se sabe la solidaridad de la familia radicaba en la dependencia económica absoluta de la esposa con respecto al marido". ${ }^{15}$ Los atributos de la vida familiar que, según el autor, se estaban contaminando por la modernidad eran el fuerte apego a la tradición, la cohesión y vigorosa solidaridad, el celoso cuidado del patrimonio, la convivencia de tres generaciones (abuelo, padres, hijos), la incuestionable autoridad del jefe de familia y la docilidad absoluta de sus dependientes (hijos y esposa). ${ }^{16}$

\footnotetext{
${ }^{14}$ Aspe, Formación, 2008, p. 143.

${ }^{15}$ Iturriaga, Estructura, 2003, p. 14.

${ }^{16}$ Ibid., p. 12.
} 
Estos argumentos vislumbran un miedo ante el posible colapso de la familia (entendida como el eje de la sociedad), y planteaban que ello podía evitarse al limitar la autonomía de las mujeres -consideradas pilar del hogar- a través del sometimiento y la sujeción económica al marido que coartarían sus posibilidades de acción, o al menos las ceñirían al arbitrio y la vigilancia de este.

Por su parte, el famoso criminólogo mexicano Alfonso Quiroz Cuarón igualmente tenía la convicción de que la participación femenina en la vida social podía tener consecuencias negativas: al abandonar el espacio doméstico las mujeres debían considerar que "la mala constitución familiar puede ser el origen de la agresividad infantil. En todas las formas de disociación familiar: niños ilegítimos, adulterinos, adoptivos." ${ }^{17}$ La obligación de las mujeres no sólo era dar a luz a los hijos sino educar a los futuros ciudadanos como sujetos de bien; es decir, al no mantener un hogar estable la madre se convertía en la responsable de la procreación de sujetos indeseables y transgresores de las formas adecuadas de socialización.

En México, desde una perspectiva moral, era generalizada la idea de que al contraer matrimonio las mujeres que se desenvolvían en otros ámbitos más allá del doméstico debían renunciar a ellos; esto es, interrumpir sus estudios, dejar las actividades políticas al margen y trabajar sólo en casos excepcionales y por necesidad, puesto que se creía que ello podría corromper el "espíritu femenino" y, por tanto, las desviaría de su misión social en el ámbito doméstico. Ciertamente, aquellos grupos, entre ellos la prensa en voz

${ }^{17}$ Quiroz, Criminalidad, 1958, p. 74. del Diario de la Vida Nacional, se mostraban atemorizados ante dicho fenómeno, pues parecían convencidos de que el abandono de la familia tradicional mexicana tendría repercusiones sociales serias como la masculinización de las mujeres o la delincuencia infantil. Desde esta lógica, se fortaleció una serie de discursos que aseguraban que la liberación femenina era un peligro para la sociedad, al tiempo que se enaltecía la domesticidad de las mujeres modernas a quienes se les adjudicaba la responsabilidad absoluta del hogar y de la educación de los hijos, aun cuando realizaran otro tipo de actividades; la plena aceptación de esta obligación ayudaría a que ellas se mantuviesen alejadas de cualquier otro tipo de actividad y, en consecuencia, a que la familia estuviese a salvo. En otras palabras, al enfatizar la trascendencia social del papel de madres, se buscaba evitar que las mujeres llegasen a preferir formas de realización personal distintas al matrimonio y la procreación, ya que ello debilitaría a la estructura familiar y social.

Sin embargo, en este punto existe una contradicción entre el discurso y la realidad en función de lo que se asumía -y pretendía-debía ser el papel de una mujer moderna; ya que, a pesar de que los movimientos feministas se silenciaban ${ }^{18}$ y se

${ }^{18}$ En 1935, mujeres del Partido Comunista (PC) y del Partido Nacional Revolucionario (PNR) crearon el Frente Único Pro Derechos de la Mujer (FUPDM), que exigía mejoras para la vida cotidiana femenina y la posibilidad de tener una mayor participación política a través del sufragio. En 1937 el FUPDM demandó el derecho al sufragio; el presidente Lázaro Cárdenas envió al Senado un proyecto de reforma constitucional para incluir a las mujeres en la definición de ciudadanía de forma que pudieran votar y ser votadas, $y$ 
difundían más abiertamente las preocupaciones de los sectores tradicionalistas, crecía de manera considerable el número de mujeres participando en la esfera pública a través del desarrollo de actividades laborales, políticas, culturales y educativas. ${ }^{19}$ Así, los discursos se convertían en un intento, de estos grupos hegemónicos, por frenar una serie de avances sociales ${ }^{20}$

aunque fue aprobado nunca se implementó. Al año siguiente, la Cámara de Diputados aprobó los derechos políticos de las mujeres; sin embargo, tampoco se pusieron en práctica. Para los años cuarenta, el FUPDM perdió visibilidad y beligerancia: apenas se mencionaban de vez en cuando sus inquietudes políticas y sus demandas se concretaron en programas de tipo social, la organización se convirtió en el Comité de Mujeres para la Defensa de la Patria y, posteriormente, en el Bloque Nacional de Mujeres, instancia dependiente del partido oficial. Véanse Cano, "Ciudadanía", 2007; Ramos, "Participación", 1994, y Tuñón, "Lucha", 2006, y Fin, 2002.

${ }^{19}$ Para dar cuenta de las cifras de mujeres desenvolviéndose en los espacios públicos que -aunque eran reducidas en comparación con las de los varones- marcaban un fenómeno irreversible y en constante crecimiento; véase Santillán, "Discursos", 2008.

${ }^{20}$ La Ley Federal del Trabajo (1931) reconocía en general los mismos derechos para hombres y mujeres con respecto a seguro por desocupación, accidente, fallecimiento o vejez; ellas podían laborar sin consentimiento del marido y se las eximía de jornadas extraordinarias y de labores consideradas peligrosas e insalubres, y se protegió la maternidad. El Código Penal (1931) buscaba castigar en función del delito cometido y no del sujeto, en los casos de aborto y de infanticidio persistían, sin embargo, consideraciones de género. En el Código Civil (1932) se dispuso que ambos cónyuges tuvieran la misma autoridad en el matrimonio para administrar y disponer de bienes, tomar decisiones y educar a los hijos; las mujeres podían conservar la patria potestad de los menores; se les otorgaba libertad para administrar sus bienes, celebrar cualquier tipo de contrato y posibilitarse un que, en el terreno cultural, recientemente comenzaban a asimilarse.

La discordancia y tensiones entre las transformaciones sociales que experimentaban las mujeres -que para entonces tenían ya un carácter irreversible- y la necesidad de consolidar la domesticidad y la maternidad como destino femenino, se evidencian en un artículo de Ana Salado Álvarez, publicado por Excélsior en 1941, en el que la autora aseguraba que la "chica moderna", además de tener ideas sanas, también ostentaba "las más torcidas y enfermas", y se la reconocía porque:

trabaja, estudia, es desenvuelta, viaja sola, habla idiomas, tiene ideas, deseos de conquistar derechos, que lee, que discute, que es inconforme, que lanza su actividad a todas direcciones y proyecta su personalidad en las demás mujeres, como la que fuma, bebe, es indolente, mal educada, sale sola con los amigos, es libre y frívola, viste con desvergüenza, desprecia el hogar y el matrimonio y cree en el control de la natalidad, en el divorcio y en iguales derechos, absolutamente hablando para hombre como para mujeres. ${ }^{21}$

Aunque la periodista reconocía que la sociedad debía modernizarse y vivir los cambios que ello traía aparejados, en lo referente a las mujeres afirmaba la existencia de

ciertas leyes que por ser universales, eternas $\mathrm{e}$ inmutables, no pueden variar. $Y$ que estas son las normas morales [...] Porque cuando se trata de su decoro, de su moralidad [...la

empleo, siempre y cuando no descuidaran la dirección y los trabajos del hogar.

${ }^{21}$ Ana Salado, "El modernismo", Excélsior, 27 de abril de 1941, $1^{\text {a }}$ secc., p. 3. Las cursivas son mías. 
mujer] es siempre la misma, ni moderna ni anticuada, sino sólo una mujer que guarda y defiende un sitio en este mundo, con el ánimo y la valentía.

Así, la escritora aseguraba que la mujer moderna aceptaba "serenamente [...] todas las obligaciones que le tocan". ${ }^{22}$ Con aseveraciones de este tipo queda claro que se buscaba, por un lado, propagar el imperativo de consolidar la unidad familiar, siguiendo la lógica del Estado, a través de la maternidad y de los esfuerzos femeninos cifrados en el hogar $y$, por otro, frenar la toma de espacios ajenos a la domesticidad al asumir que la feminidad era incompatible con el desenvolvimiento de las mujeres en los espacios públicos. Es decir, pareciera que ante el hecho de no poder negar las transformaciones sociales, consecuencia de la modernización, se buscaba estigmatizar las formas en que la mujer se adscribía a estos cambios estableciendo una diferenciación entre la buena y la mala mujer moderna.

La prensa en general -al igual que otros medios de comunicación como revistas o cine- se encargaba de encumbrar el modelo femenino considerado el correcto. $\mathrm{Al}$ respecto, la labor de Excélsior fue fundamental. Desde la década de los veinte este diario, considerado entonces el más importante de México y con una sólida visión conservadora, según anota Arno Burkholder, ${ }^{23}$ se había dedicado a enaltecer la maternidad y a protegerla de aquellas ideas que proponían un desenvolvimiento

${ }^{22}$ Ibid.

${ }^{23}$ Para una comprensión de las visiones y tendencias conservadoras de Excélsior, así como de sus relaciones con el Estado, véanse de Burkholder, "Red", 2007, y "Crecimiento", 2009. social distinto para las mujeres. En los años cuarenta colaboraba abiertamente con el Estado y con otros grupos, entre ellos la Iglesia católica, al emitir en 1941 de manera enfática su concurso "la madre prolífica".

Este tipo de discursos se contraponía a todas aquellas corrientes sociales e ideológicas que hasta el inicio de la década de los cuarenta habían buscado fervientemente la obtención de derechos políticos, laborales y sociales para el sexo femenino. Con el inicio del sexenio avilacamachista parecía que en dicha batalla, al menos en el terreno cultural, los sectores conservadores tomaban ventaja al ir difundiendo a través de diversos aparatos discursivos -entre ellos, la prensa- la necesidad de retener en el hogar a las mujeres que pretendían encontrar su realización personal fuera de este. Los concursos de exaltación a la maternidad patrocinados por Excélsior, en específico el de "la madre prolífica", apelaban, sin duda, a la necesidad del gobierno de reafirmar el discurso decimonónico sobre una supuesta determinación biológica que enraizaba al sexo femenino en la maternidad, lo cual permitía controlar el acceso a otros espacios de participación social que no fuese el doméstico. ${ }^{24}$

${ }^{24}$ Aunque en los discursos de Ávila Camacho subyacía esta idea desde su candidatura, como ya hemos mencionado, igualmente el partido opositor (PRUN) se dirigía a las mexicanas afirmando: "El gobierno te ha negado derechos políticos porque la imposición [sic] sabe que tú no venderías por ningún precio el porvenir de tus hijos [...]. Tu revancha consistirá en hacer valer tus derechos de mexicana, de mujer, de madre, de esposa, de amante, de hermana, por conducto de los hombres que amas y sobre los que puedes influir." "Mujer mexicana", Excélsior, 25 de junio de 1941, 1a. secc., p. 3. 


\section{MATER DOLOROSA}

En el ambiente de la veneración de la figura materna, el periódico Excélsior tuvo una actuación preponderante como difusor ideológico y como agente de comercialización al acuñar, difundir y promover el Día de la Madre. En 1922, Rafael Alducín, fundador del Diario de la Vida Nacional, sugirió que se consagrara el 10 de mayo, siguiendo el ejemplo de Estados Unidos, para "rendir homenaje de afecto y de respeto a la madre; y pide la cooperación de sus colegas y del público para realizar ese levantado propósito". ${ }^{25}$ Cabe remarcar que el impreso abanderaba la causa conservadora del ala derechista de la sociedad que se oponía abiertamente al sector que pretendía fomentar una mejor situación social para las mexicanas desde Yucatán: los congresos feministas de 1916, la promoción de una educación femenina de corte racionalista y la repartición en marzo de 1922 de un folleto sobre control de la natalidad y educación sexual para mujeres. Como respuesta ante dicha situación, la nota continuaba diciendo:

Hoy que en el extremo meridional del país se ha venido emprendiendo una campaña suicida y criminal contra la maternidad, cuando en Yucatán elementos oficiales no han vacilado en lanzarse a una propaganda grotesca, denigrando la más alta función de la mujer que no sólo consiste en dar a luz, sino en educar a los hijos que forma de su carne $[\ldots]$ no hemos de ninguna manera llegado a esa aberración que predican los "racionalistas" exaltados, sino que lejos de

25 "El día de las madres", Excélsior, 13 de abril de 1922, 2a. secc., p. 10. ello sabemos honrar a la mujer que nos dio vida. $^{26}$

De esta manera, Excélsior acaudillaba la vigilancia y la defensa de la moral tradicional que consideraba amenazada por las transformaciones promovidas por los nuevos ideales revolucionarios. A partir de entonces, este impreso se ocupó de encabezar y dirigir las celebraciones a las madres mexicanas, afanándose por recordar a sus lectores, semanas antes a cada 10 de mayo, la importancia de

considerar los sacrificios inherentes a la maternidad, la misión de dulzura y de amor que desempeña la mujer hacia sus hijos, misión que comienza antes del nacimiento de estos y no termina sino con la muerte. No hay sacrifico suficientemente grande para el corazón de una madre. ${ }^{27}$

Año tras año fueron aumentando los anuncios de regalos especiales para las madres (pasteles, chocolates, medias, vestidos, joyas, aparatos electrodomésticos), mientras que otros diarios fueron sumando sus felicitaciones para ellas cada 10 de mayo. Así, se formulaba a través de la prensa una campaña ideológica en torno a la maternidad liderada por el Diario de la Vida Nacional, que incluía a otras instituciones clave como la escuela, la Iglesia y la beneficencia, así como al mundo del espectáculo y del comercio ${ }^{28} \mathrm{y}$, durante el gobierno de Ávila Camacho, ciertos

${ }^{26} \mathrm{Ibid}$. Para profundizar en la discusión suscitada en la prensa en torno a dicho tema véanse de Acevedo, Mayo, 1982, y "Mayo", 2002.

27 "El día de las madres", Excélsior, 13 de abril de 1922, 2a. secc., p. 10.

${ }^{28}$ Acevedo, Mayo, 1982, p. 32. 
organismos políticos también se verían inmiscuidos.

Al comienzo de los años cuarenta, Excélsior se jactaba de ser el creador del Día de la Madre:

numerosas organizaciones, sociedades científicas y literarias, particulares, etc., nos han enviado cartas llenas de entusiasmo adhiriéndose a la noble y generosa idea lanzada por el comité pro monumento a la madre mexicana, en el sentido de que las cámaras expidan un decreto instituyendo día de fiesta nacional el 10 de mayo, fecha gloriosa en que, a iniciativa de EXCÉLSIOR, año por año se celebra el DÍA DE LAS MADRES. ${ }^{29}$

Por tanto, se erigía como el eje articulador de los festejos públicos realizados para las madres mexicanas y daba consejos para la selección de los regalos y de los agasajos adecuados que ellas debían recibir. Pero, más importante aún, resolvía cómo debían vivir las propias mujeres su maternidad y lo que el resto de la sociedad debía esperar de ellas: "Mater dolorosa, la madre sabe nutrir su fe con su amargura, cultivar su esperanza con su llanto. Porque en ella palpita el futuro, y de la noche de su dolor surge el luminoso amanecer de la humanidad." 30

La mercantilización del Día de la Madre se expandía y vigorizaba; las mexicanas con hijos recibían felicitaciones de casas comerciales, autoridades políticas y civiles, así como las bendiciones de la alta jerarquía católica. En los 10 de mayo de

29 "Activa gestión para que se declare fiesta nacional", Excélsior, 14 de abril de 1941, 2a. secc., p. 1. Mayúsculas en el original.

30 "El día de las madres", Excélsior, 10 de mayo de 1941, 1a. secc., p. 4.
1944 y 1947 se publicó en la primera plana del Excélsior una fotografía del papa Pío XII enviando la bendición a las madres mexicanas quienes, según los dirigentes eclesiásticos, debían recibir a todos los hijos que Dios les mandara. ${ }^{31}$ De esta forma, el periódico se convertía en un espacio en el que se legitimaban los ideales referentes a la maternidad promovidos por las elites políticas, las cuales se encontraban en sintonía con la postura católica. La exacerbación de esos discursos, difundidos a través de las páginas del rotativo, constataba el triunfo del conservadurismo frente a las pretensiones reformistas de los anteriores gobiernos de corte socialista y con ideas "exóticas". 32

Sin duda, su labor fue fundamental en la consolidación del ideal femenino de la época; no obstante, debemos reconocer que ello fue posible gracias al ambiente conservador que se expandía e imperaba nuevamente en México. Por su parte, a la esposa del primer mandatario, Soledad Orozco, le gustaba proporcionar gratificaciones a las madres humildes y enviar saludos "cariñosos" a través de la prensa a las madres mexicanas en cada celebración a la maternidad. ${ }^{33}$ En 1942 Excélsior aseguraba que la primera dama había inspirado a su marido para que ordenara a las Secretarías de Hacienda y de Asistencia Pública que firmasen un acuerdo con el Nacional Monte de Piedad para que 6000 máquinas de coser empeñadas fueran devueltas a sus dueñas -madres, por supuesto- el 10 de mayo; el Estado cubriría

31 Torres, "Familia", 2006, p. 186.

32 Término acuñado por el ex presidente Abelardo Rodríguez durante la era avilacamachista. José Agustín, Tragicomedia, 2007, p. 24.

${ }^{33}$ Véase Sefchovich, Suerte, 2007, pp. 282-300. 
los gastos. ${ }^{34}$ Dos años más tarde, los artículos liberados por la casa de empeños fueron planchas, vestidos, abrigos, rebozos, ropas de cama. ${ }^{35}$ En 1943, doña Soledad regaló estufas mientras se escuchaba el grito de "bendita sea"; 36 en 1945 , repartió 20000 despensas populares para hogares humildes, ${ }^{37}$ y en 1946 se leía un encabezado que decía "devolución de todas las prendas que han sido empeñadas por madres pobres. Altruista rasgo de la esposa del señor presidente que beneficiará a 50000 personas." 38

De otro lado, el Diario de la Vida $\mathrm{Na}$ cional había estado realizando, desde la década anterior, diferentes concursos que tenían como finalidad "enaltecer y solemnizar el Día de la Madre", ${ }^{39}$ con la pretensión de elevarlo al rango de festejo nacional; ${ }^{40}$ entre ellos, los hubo de poesía y relatos infantiles para elogiar a las madres, también se glorificaba a la madre más joven, la más anciana o la más fértil. Sin embargo, fue hasta el sexenio avilacamachista cuando estos certámenes fueron publicitados con mayor énfasis y cobertura, al tiempo que obtuvieron mayor apoyo de las autoridades políticas, ya fuera otorgando premios, entregándolos o simplemente

34 "6000 máquinas de coser se devolverán a sus dueñas", Excélsior, 9 de mayo de 1942, 1a. secc., p. 1.

35 "Regalo de la primera dama a las madres", Excélsior, 10 de mayo de 1944, 1a. secc., p. 1.

36 "La primera dama regaló 17 mil estufas", Excélsior, 11 de mayo de 1943, 1a. secc., p. 1.

37 "Regalará despensas a las madres la primera dama", Excélsior, 9 de mayo de 1945, 1a. secc., p. 1. 38 "Devolución de todas la prendas", Excélsior, 10 de mayo de 1946, 1a. secc., p. 1.

39 "Deben remitirse con toda oportunidad", $E x$ célsior, 12 de abril de 1941, 2a. secc., p. 1.

40 "Activa gestión para que se declare fiesta nacional", Excélsior, 14 de abril de 1941, 2a. secc., pp. 1-2. aplaudiendo la moción del diario. La explicación probablemente podamos encontrarla en el hecho de que Ávila Camacho "nunca se pronunció por la igualdad ciudadana entre los sexos" ${ }^{11}$ a diferencia, por ejemplo, de Cárdenas, su antecesor, quien estaba convencido de las posibilidades de desarrollo de las mujeres y de lo positivo de la participación femenina en la vida social y política del país. ${ }^{42}$ Ese escenario permitía al diario promover abiertamente una visión conservadora respecto a la misión femenina circunscrita al ámbito doméstico.

Por otro lado, el impreso se encargó de destacar la relevancia que tenían estos concursos para el país, sobre todo el de "la madre prolífica" que se encontraba en sintonía con las políticas pronatalistas del gobierno, que desde el sexenio anterior se había impuesto como una meta importante fomentar el aumento de la población fundamentalmente a través del crecimiento natural, para lo cual se "promoverán las medidas adecuadas al fomento de los matrimonios, aumento de la natalidad, protección biológica y legal de la infancia". ${ }^{43}$ Estas políticas tenían como marco de referencia la creciente inquietud mostrada por el gobierno por regular la natalidad y la maternidad, en su pretensión de favorecer la procreación de niños saludables y productivos para la nación. ${ }^{44}$ Alexandra Stern analiza una serie de mecanismos eugené-

${ }^{41}$ Cano, "Ciudadanía", 2007, p. 181.

${ }^{42}$ Ibid., pp. 171-174.

${ }^{43}$ Ley, 1937, art. 4, p. 6.

${ }^{44}$ Es interesante el análisis propuesto por Michel Foucault sobre el poder biopolítico desplegado por los Estados modernos a través del cual se buscaba regular la natalidad, la mortalidad y la longevidad de los integrantes de la nación. Véanse de Foucault, Genealogía, 1996, pp. 193-214, y Nacimiento, 2007. 
sicos alentados por el Estado a partir de 1920 -y que se extendieron hasta la década de los cincuenta- a través de los cuales se "buscaba reorientar la conductas de las madres" ${ }^{45}$ para lograr dicho objetivo.

En este contexto, en el mencionado certamen de Excélsior, las mujeres competían en función de su maternidad, considerada la cualidad femenina por excelencia: mientras más hijos mejor mujer y, por tanto, se la debía premiar. De esta manera, con la difusión e imposición de este modelo femenino como el ideal, se consolidaba la alianza entre el ala conservadora de la sociedad, la prensa y el Estado.

\section{LA MADRE PROLÍFICA: UN PROPÓSITO PATRIÓTICO DE GRAN ALCANCE}

Para celebrar el 10 de mayo de 1941, en el primer año del gobierno avilacamachista, se promocionó con gran entusiasmo y exaltación sin precedentes un concurso que tenía la finalidad de premiar a la madre con 20 hijos vivos: "la madre prolífica". A la par se orquestó la creación de poemas infantiles ilustrados para la madre y la condecoración al primer niño nacido el 10 de mayo. En los primeros días de abril se leyó el siguiente encabezado:

Entusiasmo por la celebración del 10 de mayo

Un propósito patriótico de gran alcance

Los concursos preparados por Excélsior tienen una doble finalidad

El de las madres prolíficas tiende a resolver un grave problema. ${ }^{46}$

${ }^{45}$ Stern, "Madres", 2002, p. 303.

46 "Entusiasmo por la celebración", Excélsior, 10 de abril de 1941, 2a. secc., p. 1.
En el anuncio se hacía hincapié en la necesidad, por un lado, de venerar a las madres y, por otro, en los beneficios que el concurso traería a la patria; por ello, la Secretaría de Asistencia Pública premiaría "enalteciéndolas, dignificándolas, a las madres prolíficas, buscando de esta forma la resolución de uno de nuestros grandes problemas: el aumento de población en nuestro vasto territorio". ${ }^{47}$ Esta nota es reveladora en cuanto permite inferir ciertos rasgos de las políticas gubernamentales de población.

Podemos suponer que esta campaña de fomento de la natalidad como fórmula para multiplicar el número de mexicanos, impulsada a través de "la madre prolífica" de Excélsior, se incorporaba a los expresos intereses del Estado para fortalecer a los habitantes y engrosar su número en aras del proyecto industrial. Luis Fermín CuéIlar aseguraba, en su texto $E l$ seguro social y la maternidad (1945), que las mujeres satisfacían "un valor fundamental para la integración del pueblo [...al garantizar] al trabajador su vida". ${ }^{48}$ En el marco de un evento dedicado a la madre y al niño, en mayo de 1941, el doctor Federico Villaseñor, miembro del Instituto Nacional de Nutriología, ponía en relieve la importancia del cuidado que las madres debían tener con el crío, tanto física como moralmente, para hacer de él "un hombre útil a la patria". ${ }^{49}$ Por su parte, el secretario de Asistencia Pública, Gustavo Baz, pedía a las madres "nos ayude[n] a cuidar a sus hijos", ya que "México necesita nuevas

${ }^{47}$ Ibid.

${ }^{48}$ Luis Fermín Cuéllar citado en Stern, "Madres", 2002, p. 327.

49 "Salubridad inauguró ayer la semana de la higiene", Excélsior, 5 de mayo de 1941, 1a. secc., p. 5. 
generaciones de hombres fuertes, física y mentalmente". ${ }^{50}$

Al cierre de los años cuarenta el crecimiento demográfico casi se duplicaba por primera vez en el siglo: en 1921 había 14335000 habitantes; en 1930 , 16553000 ; en 1940,19654000 , y en 1950 llegó a $25791000 .^{51}$ Ello respondía a diversos factores como la disminución de la mortalidad infantil, la mejora en los servicios de salud (vacunación, medicinas, control de enfermedades), avances en la higiene y urbanización (agua potable y alcantarillado), así como mayores fuentes de empleo, consecuencia de la creación de nuevas industrias, que se traducían en aumento en los niveles de vida, sobre todo en las ciudades. ${ }^{52}$ No obstante, consideramos que este incremento igualmente encontró eco en el plano cultural e ideológico.

En este sentido, al promover el aumento de nacimientos, Excélsior fortalecía la idea de una feminidad destinada absolutamente a la maternidad; ello en sintonía con los discursos hegemónicos políticos que consideraban a la familia como el eje principal de la sociedad y como símbolo de diferenciación cultural y unidad nacional. A decir del presidente Ávila Camacho, la familia era "uno de los valores morales de nuestra organización social y merecerán las más acendradas garantías de la ley y la administración". ${ }^{53}$ En tanto el Diario de la Vida Nacional afirmaba que "la madre es sostén de la unidad hogareña y vigía de la educación", sobre todo en estos tiempos en los que "los valores se encuen-

50 "Mensaje a las madres mexicanas, en su día", Excélsior, 10 de mayo de 1941, 1a. secc., p. 3.

${ }^{51}$ Cincuenta, 1963, p. 22.

52 Aboites, "Último", 2008, pp. 274-275.

${ }^{53}$ Ávila, 1940, p. 40. tran invertidos". De esta suerte, el periódico se convertía en un espacio al servicio de la elite política que buscaba promover -y legitimar- el "culto al santo hogar", ${ }^{54}$ la maternidad y las familias abundantes.

Por otro lado, nos parece fundamental resaltar otra cara del concurso: para acreditar a sus hijos las posibles madres prolíficas debían remitir las

actas de nacimiento, fe de bautismo o cualquier otro documento fehaciente que pueda servir de comprobante legal de que existen esos hijos. Puede aceptarse testimonio del juez del Registro Civil o de las autoridades municipales del lugar. ${ }^{55}$

Ello evidencia que, aun cuando se aceptaban actas bautismales como certificado oficial, la instancia civil estaba por encima de la religiosa en tanto que, en caso de ausencia de los documentos solicitados, aquella era la única que podía acreditar los nacimientos.

Efectivamente, el Estado estuvo vinculado al certamen de las madres prolíficas a través de diversas instancias gubernamentales. En primer orden, desde su lanzamiento, la Secretaría de Asistencia Pública se anunciaba como la responsable de otorgar los diplomas y medallas de oro, plata y bronce para las ganadoras. ${ }^{56}$ Días más tarde, el secretario de Gobernación, Miguel Alemán, al reconocer la importancia de la labor de poblar México a través de este concurso, según el diario, decidió otorgar dinero en efectivo a las dos

\footnotetext{
54 "Venerar a las madres es hacer labor patria", Excélsior, 25 de abril de 1941, 2a. secc., p. 1.

55 "Tres concursos de Excélsior", Excélsior, 9 de abril de 1941, 2a. secc., p. 3.

${ }^{56}$ Ibid.
} 
madres más prolíficas del país. ${ }^{57}$ Por su parte, el secretario de Educación, Luis Sánchez Pontón, aseguró haber enviado una circular a los directores de las escuelas primarias para que se asistiera a los infantes en la creación de los poemas y los dibujos para alabar a sus madres; ${ }^{58}$ así, mientras las mujeres procreaban, a los niños se los enseñaba a honrar los "sacrificios" de sus madres. Petróleos Mexicanos también se sumó al festejo, y donó 50 estufas Petromex para las mexicanas con un mayor número de hijos. ${ }^{59}$

El poder de convocatoria que generó el certamen fue enorme. La gran cantidad de fotografías enviadas al rotativo (de las cuales sólo se pudieron publicar unas cuantas, aseguraban los redactores, por cuestiones de espacio), permite comprobar, por un lado, el profundo valor de la maternidad existente en México y, por otro, que la publicación de la fotografía familiar en el diario se convertía en un magnífico escaparate que les permitiría mostrarse ante la sociedad como familias ejemplares.

El 22 de abril se divulgaron los dos primeros retratos de madres con sus vástagos: Laura Suárez con doce y la señora de Jiménez Nochebuena con 16, las cuales pasaron a formar "La legión de honor de las madres prolíficas". Con el paso de los días, continuó la exhibición de imágenes que mostraban a numerosas familias ro-

${ }^{57}$ Quinientos pesos al primer lugar y 100 al segundo; a estos últimos el diario sumaría 150. "Tres grandes concursos para la madre", Excélsior, 18 de abril de 1941, 2a. secc., p. 1.

58 "Mayor colaboración oficial", Excélsior, 23 de abril de 1941, 2a. secc., p. 1.

59 "Más obsequios a las madres prolíficas de México", Excélsior, 24 de abril de 1941, 2a. secc., p. 1. deando a la madre responsable de esa prole: mujeres con diez, doce, quince y 17 hijos, pero no con 20. Excélsior lamentaba que en el país fuese escaso el número de mujeres con más de esta última cantidad de hijos vivos y señalaba que por ese motivo se repartirían los premios entre aquellas que tuvieran más de diez. ${ }^{60}$

Cabe anotar que, aun cuando así lo refería el periódico, ello no es indicativo de la fertilidad de las madres mexicanas de los diversos sectores sociales. ${ }^{61}$ De cualquier manera, México era un país de familias numerosas: ${ }^{62}$ aproximadamente doce

60 "Modificación a una de las bases", Excélsior, 1 de mayo de 1941, 2a. secc., p. 1.

${ }^{61}$ Desafortunadamente las fuentes hemerográficas no brindan la información que nos permita conocer las características y condiciones de vida de las mujeres que participaban en el concurso, así como sus posibilidades de desarrollo fuera del hogar. Sin embargo, es posible suponer que ellas pertenecían a las clases medias urbanas, en razón de que ellas tenían mayores posibilidades de acceso a los periódicos, ya que en dichos sectores el alfabetismo era mayor; asimismo, la gente podía disponer del recurso económico para la adquisición de los periódicos. En tal sentido, aunque se desconoce el tiraje del rotativo, suponemos que el número de lectoras de Excélsior era reducido. En primer lugar, a finales de 1940 existían en México 1093 publicaciones periódicas, de las cuales había 426 en el Distrito Federal, entre estas se encontraba Excélsior (Ochoa, Reseña, 1968, p. 151). En segundo, de acuerdo con el censo de 1940, menos de la mitad de la población del país eran alfabetos, en su mayoría varones (Secretaría, Séptimo, 1953, p. 91). Por último, no hay registro de la cantidad de lectores de prensa -ni del sector social al que pertenecían- ni qué periódicos preferían, aunque sabemos que en algunos casos las personas analfabetas pudieron acceder a narraciones orales de los contenidos de los diarios ello no supone ni su adquisición ni su lectura cotidiana.

${ }^{62}$ En 1939 la tasa global de natalidad en el país era de 6.10 hijos por mujer, y para 1952 aumentó 
de los casi 20000000 de personas que registró el censo de 1940, provenían de familias de entre cinco y más de once integrantes. ${ }^{63}$

Al comenzar el mes de mayo aumentaba el entusiasmo en las páginas del diario. En los días 6 y 7 se publicó una plana completa con fotografías de diversas madres con sus más de diez o quince hijos; el día siete se anunció que las localidades para la fiesta organizada para las "cabecitas blancas" en el Teatro Alameda estaban agotadas. Finalmente, llegó la fecha esperada, que el diario ya nombraba como fiesta nacional (con lo cual se reafirmaba el discurso hegemónico político, moral y religioso sobre la maternidad), asistieron personalidades del mundo del espectáculo, de la cultura y de la política. En representación del secretario de Asistencia Pública, Gustavo Baz, el licenciado Sierra Rojas dio un "brillante" discurso donde enfatizó que la maternidad

simboliza la unión de todos los mexicanos [...] lo que nuestra nacionalidad tiene de más bello, de más real, es el profundo cariño a nuestras madres, que al crear vínculos afectivos poderosos hace de la familia, la base más sólida del Estado. [...Es por ello] que lo que somos y lo que podemos ser, se lo debemos íntegramente al cariño, al trabajo y a la abnegación de nuestras madres. [...] nada

a 6.4 (Anuario, 1999 , p. 81). Hacia mediados del decenio de los cincuenta, México tenía una de las más altas tasas de natalidad en América Latina con 6.8 hijos por mujer, mientras que, por ejemplo, en Argentina era de 3.2 y en Chile de 5.1 (FlaCsO, Mujeres latinoamericanas en cifras, disponible en <http://www.eurosur.org/FLACSO/ mujeres $/>$ ).

${ }^{63}$ Secretaría, Sexto, 1943, p. 14. piden ellas y todo lo reclaman para sus hijos. $^{64}$

Ese 10 de mayo de 1941 el Excélsior divulgó la lista de "honor" con las madres más prolíficas de México: Mercedes Morales, de Sinaloa, con 17 hijos vivos obtuvo el primer puesto; en segundo lugar, empataron seis madres con 16 vástagos cada una; $y$, en orden descendente, fueron entregándose las estufas, las medallas y los diplomas a un total de 185 madres con más de diez hijos vivos. En la primera plana se mostraba la felicitación de doña Soledad Orozco a través de la cual deploraba no poder presidir la festividad por tener que asistir a un evento semejante de carácter familiar.

\section{EXCÉLSIOR COMO AGENTE IDEOLOGIZANTE}

En respuesta a la preocupación mostrada por Ávila Camacho durante su candidatura, y ante lo que él consideraba una carencia de respeto a la madre mexicana, el trabajo aleccionador del impreso perseguía tres objetivos: engrosar las familias, fortalecer la responsabilidad de las mexicanas por su prole e inculcar en los futuros ciudadanos el amor y respeto a su madre.

A lo largo de la década se celebró en varios 10 de mayo el certamen de "la madre prolífica", que estuvo acompañado de otros concursos más: en general, la elaboración de poemas o dibujos infantiles para las madres y del "Niño 10 de Mayo".

${ }^{64}$ Andrés Serra Rojas, "Discurso en honor de las madres mexicanas", Excélsior, 11 de mayo de 1941, 1 a. secc., p. 14. 
$\mathrm{Al}$ involucrar a los chicos en los primeros, Excélsior aseguraba que

venerar a las madres es hacer labor patria; -por ello- en el hogar, lo mismo que en la escuela, y en todas partes, debe nacer la incitación para que los niños cumplan con este deber de gratitud y de veneración a los seres que les dieron vida. ${ }^{65}$

Con estas miras, en 1941 el diario agrandó la apoteosis a las madres al gratificar a más de ochenta infantes por sus poemas y dibujos dedicados a sus progenitoras.

El "Niño 10 de Mayo" premiaba a la mujer que diera a luz al primer bebé el Día de la Madre. Ser la ganadora de este concurso debía ser más que jubiloso para la afortunada; por ello era visitada por redactores y fotógrafos de Excélsior para darle cobertura al evento en las siguientes horas del alumbramiento. El regocijo de la madre -además de un premio de 500 pesos-, a ojos del rotativo, correspondía a que dicho nacimiento, el primero en el día de la celebración a la maternidad, convertía a la progenitora en la madre número uno entre todas.

En 1941, el "Niño 10 de Mayo" fue una niña. Los redactores de Excélsior se habían enterado de que, semanas antes del alumbramiento, el padre había solicitado al presidente estadunidense Franklin D. Roosevelt y su esposa que seleccionaran el nombre de su futuro hijo; a partir de esa información aseguraban que la recién nacida podría ser apadrinada por los Roosevelt. ${ }^{66}$

65 "Venerar a las madres es hacer labor patria", Excélsior, 25 de abril de 1941, 2a. secc., p. 1.

66 "Será ahijada de Roosevelt", Excélsior, 11 de mayo de 1941, 2a. secc., pp. 1 y última.
Esta nota permite advertir el papel político e ideológico que desempeñaba el rotativo al manifestar su simpatía por el país vecino en el marco de unas delicadas relaciones internacionales entre ambas naciones y con el trasfondo de un sentimiento antiestadunidense generalizado en México.

Otra muestra del vínculo de estos concursos con la situación política se dio en 1942. Ante los presagios de la incursión de México en la guerra, se emitió el certamen de las "madres heroicas", a través del cual se convocaba a los familiares para crear relatos en los que se narrase un "rasgo de abnegación o de heroísmo ejemplar, consumado por una madre viviente". ${ }^{67}$ Así, se emparentaba la "noble labor" de las madres con la defensa de la libertad de las naciones sojuzgadas por los "aplastantes cascos de las desenfrenadas bestias apocalípticas, que llevan a su zaga hambre, guerra, peste y desolación". 68

A lo largo de los siguientes años del sexenio avilacamachista los concursos fueron adecuándose a las necesidades políticas y sociales del momento: en 1943, con México ya inmiscuido en la guerra, se premiaría a la mexicana con más hijos en el servicio militar; en 1944 y 1945, regresaría el de la madre prolífica, sólo que ahora no con más hijos, sino con más descendientes vivos y, en 1946, a la madre prolífica se le sumaron los de la más anciana y el de la mujer con más hijos condecorados en el ejército. A la par de estos concursos estelares se mantuvo constante el del "Niño 10 de Mayo" y se organizaron de dibujos, poemas y composi-

67 "Excélsior convocará a tres grandes concursos", Excélsior, 2 de abril de 1942, 2a. secc., p. 1.

68 "Homenaje sin precedentes", Excélsior, 1 de abril de 1942, 2a. secc., p. última. 
ciones infantiles, de fotografía y de guión cinematográfico que tuvieran como protagonista a la madre, así como de pensamientos a la madre escritos por recién alfabetizados. Este último se ofreció en 1946, sin duda, con la finalidad de aminorar las dificultades que habían entorpecido la campaña de alfabetización lanzada en marzo del año anterior por el gobierno a través de la Secretaría de Educación, y que para entonces sólo había conseguido hacerlo con 200000 mexicanos de los $9000000(47.8 \%)$ que no sabían leer y escribir. ${ }^{69}$

Los certámenes de Excélsior fueron variando sus modalidades a lo largo de los años, hasta su conclusión en 1971. En las últimas tres emisiones, por fin, se le dio voz y participación activa a las madres -precisamente cuando comenzaban a manifestarse en el país los movimientos de la segunda ola del feminismo. En 1969 debían plasmar en 25 líneas las mejores propuestas para educar a sus hijos; en 1970, narrar cómo podían encauzarlos al tiempo que ellas trabajaran; en 1971, escribir un relato referente al mundo que ellos heredarían. Este último año, el grupo feminista Mujeres de Acción Solidaria se manifestó, a pesar de la negativa del Departamento del Distrito Federal, frente al monumento a la ma$\mathrm{dre}^{70}$ en contra del mito que se había construido en torno a la maternidad, se-

${ }^{69}$ José Agustín, Tragicomedia, 2007, p. 52; véanse Krauze y Lupone, Manuel, 1998, min. 11' 30, y Torres, Pensamiento, 1985 , pp. 69-75.

${ }^{70}$ La construcción del monumento a la madre fue promovido con insistencia por el Excélsior desde 1932; su erección se logró finalmente en 1948. Acevedo, Mayo, 1982, pp. 46, 63, y Cano, "Ciudadanía", 2007, pp. 48, 54. gún lo registró El Día. ${ }^{71}$ En cambio, el Diario de la Vida Nacional, al igual que otros importantes impresos como $E l$ Novedades y El Universal, omitió el registro del acontecimiento.

Finalmente, al año siguiente, y tras cuatro décadas de orquestación de la maternidad en México a través de sus concursos, el impreso retiraba de escena las competencias, probablemente cediendo ante los inminentes cambios sociales y políticos que evidenciaban cada vez más la exigencia de las mexicanas por acceder a distintos espacios de desarrollo para sí mismas, además del doméstico.

\section{CONSIDERACIONES FINALES}

En los años cuarenta comenzaba a revertirse la educación conocida como racionalista para el sexo femenino promovida por sectores políticos progresistas durante las dos décadas anteriores. El gobierno avilacamachista, en contubernio con los sectores derechistas y conservadores, la Iglesia y el periódico Excélsior, alentó en cambio a las mujeres para que concibieran todos los hijos que su cuerpo les permitiese.

El vínculo entre gobierno y prensa creado al inicio del gobierno de Ávila Camacho en torno a los concursos de maternidad emitidos por Excélsior, advierte el rumbo que tomarían las políticas de género de los gobiernos en México entre las décadas de los cuarenta y cincuenta; igualmente, evidencia el uso que las elites gobernantes dieron a la prensa para promover su visión hegemónica al respecto. En este sentido, podemos afirmar que

71 "Grupo de madres afirma: es mucha piedra y pocos derechos", El Día, 9 de mayo de 1971, p. 2. 
existió un expreso interés por limitar, al menos en los planos ideológico y cultural, la realización social de las mexicanas al ámbito doméstico, buscando evitar con ello -y quizás obstaculizar- su desenvolvimiento en otros espacios públicos, bajo el argumento del desmoronamiento de la familia tradicional. De esta manera, la maternidad era entendida como la obligación femenina por procrear el mayor número posible de hijos sanos física y mentalmente que fueran productivos para la nación, y por mantener la estructura familiar sólida y estable.

El certamen de las madres prolíficas colaboraba, en primera instancia, con los grupos hegemónicos políticos y sociales para favorecer el papel ideal de la mujer como madre y como eje rector de la familia; así, se consolidaba la idea de que las actividades domésticas y de procreación les pertenecían por "naturaleza", antes que aquellas que sirvieran para su desarrollo educativo o profesional. En segundo término, reafirmaba la importancia de acrecentar los nacimientos en función de las políticas pronatalistas del gobierno avilacamachista. En tercero, y en sintonía con lo anterior, se reconocía al Registro Civil como la instancia legítima para la inscripción de los mexicanos recién nacidos.

Excélsior, el Diario de la Vida Nacional, fue conformando "La legión de madres de honor" con todas aquellas mujeres mexicanas con un mayor número de hijos. Esto nos permite advertir el papel ideologizante que el impreso tuvo como promotor de los discursos y proyectos oficialistas y de los grupos conservadores, así como de la importancia social y moral que, a pesar de los intentos de cambio, aún revestía a la maternidad hacia el cierre de la primera mitad del siglo Xx en México.

\section{FUENTES CONSULTADAS}

\section{Hemerografía}

Excélsior, México.

El Día, México.

El Universal, México.

Novedades, México.

\section{Bibliografía}

-Aboites Aguilar, Luis, "El último tramo, 19292000" en Pablo Escalante et al., Historia mínima de México, Colmex, México, 2008, pp. 262-302.

Acevedo, Marta, "El 10 de mayo" en Griselda Gutiérrez Castañeda (coord.), Feminismo en México. Revisión bistórico-crítica del siglo que termina, PUEG-UNAM, México, 2002, pp. 39-51. , El 10 de mayo, SEP/Martín Casillas Editores, México, 1982.

-Anuario bistórico de México, INEGI, México, 1999, t. 1.

-Aspe Armella, María Luisa, La formación social y política de los católicos mexicanos. La Acción Católica Mexicana y la Unión Nacional de Estudiantes Católicos, 1929-1958, uI, México, 2008. - Ávila Camacho y su ideología. Jira [sic] electoral, PRI, México, 1940.

-Blanco Figueroa, Francisco (dir.), Mujeres mexicanas del siglo XX, Editorial Edicol/UAM/IPN/ uNAM/UAEMEX/UANL/UAEM/UACD, México, 2001, tt. I-IV.

-Burkholder de la Rosa, Arno, "Construyendo una nueva relación con el Estado: el crecimiento y consolidación del diario Excélsior (1932-1968)", Secuencia, Instituto Mora, núm. 73, enero-abril de 2009, pp. 87-104.

"La red de los espejos. Una historia del diario Excélsior (1916-1976)", tesis de doctorado, Instituto Mora, México, 2007.

-Cano, Gabriela, "Ciudadanía y sufragio femenino: el discurso igualitario de Lázaro 
Cárdenas" en Marta Lamas (comp.), Miradas feministas sobre las mexicanas del siglo $\mathrm{XX}$, FCE/CONACULTA, México, 2007, pp. 151-190.

, "Revolución, feminismo y ciudadanía en México, 1915-1940" en Georges Duby y Michelle Perrot (dirs.), Historia de las mujeres, Taurus, Madrid, 2000, vol. v, pp. 747-762.

-Cincuenta años de la revolución mexicana en cifras, NAFInSA/Presidencia de la República, México, 1963.

-Código Civil de 1932, Porrúa, México, 1955.

-Código Penal de 1931, Editorial Botas, México, 1936.

-Foucault, Michel, Genealogía del racismo, Editorial Altamira, Argentina, 1996. Argentina, 2007.

El nacimiento de la biopolítica, FCE,

-Gutiérrez Castañeda, Griselda (coord.), Feminismo en México. Revisión histórico-crítica del siglo que termina, PUEG-UNAM, México, 2002.

-Herrera Feria, Ma. de Lourdes (coord.), Estudios históricos sobre las mujeres en México, BUAP, México, 2006.

-Iturriaga, José E., Estructura, social y cultural en México, INEHRM, México, 2003 (1a. edición facsimilar FCE/NAFINSA, 1951), .

-José Agustín, La tragicomedia mexicana, la vida en México de 1940 a 1970, Planeta, México, 2007.

-Labor Legislation of Mexico, Gobernment Print Office, Washington, 1932.

-Lamas, Marta (comp.), Miradas feministas sobre las mexicanas del siglo $\mathrm{XX}, \mathrm{FCE} / \mathrm{CONACULTA}$, México, 2007.

-Ley General de Población, Cámara Nacional de Comercio y de Industria de la Ciudad de México, México, 1937.

- Los presidentes de México ante la nación, XIVI Legislatura de la Cámara de Diputados, México, 1966.

-Meyer, Lorenzo, "La institucionalización del nuevo régimen" en Historia general de México, Colmex, México, 2000, pp. 823-879.
-Ochoa, Moisés, Reseña bistórica del periodismo mexicano, Porrúa, México, 1968.

-Quiroz Cuarón, Alfonso, La criminalidad en la república mexicana, IIS-UNAM, México, 1958.

-Ramos Escandón, Carmen, "La participación política de la mujer en México: del fusil al voto 1915-1955", Boletín Americanista, Universidad de Barcelona, núm. 44, 1994, pp. 155-169.

-Rocha, Martha Eva, "Las mexicanas en el siglo XX" en Francisco Blanco Figueroa (dir.), Mujeres mexicanas del siglo XX, Editorial Edicol/ UAM/IPN/UNAM/UAEMEX/UANL/UAEM/UACD, México, 2001, t. IV, pp. 89-159.

-Santillán, Martha, "Discursos de redomesticación femenina durante los procesos modernizadores en México, 1946-1958", Historia y Grafía, Universidad Iberoamericana, núm. 31, diciembre de 2008, pp. 103-132.

-Secretaría de Economía, Séptimo censo general de población, México, 1953.

-Secretaría de la Economía Nacional, Sexto censo de población 1940, México, 1943.

-Sefchovich, Sara, La suerte de la consorte, Océano, México, 2007.

-Stern, Alexandra, "Madres conscientes y niños normales: la eugenesia y el nacionalismo en el México posrevolucionario, 1920-1940" en Laura Cházaro (ed.), Medicina, ciencia y sociedad en México, siglo XIX, Colegio de Michoacán/Universidad Michoacana de San Nicolás de Hidalgo, México, 2002.

-Torres, Blanca, Historia de la revolución mexicana (1940-1952): México en la segunda guerra mundial, ColmeX, México, 2005, t. 19.

-Torres Septién, Valentina, "Una familia de tantas. La celebración de las fiestas familiares católicas en México (1940-1960)" en Pilar Gonzalbo Aizpuru (dir.), Historia de la vida cotidiana en México, t. v, vol. I, Siglo XX. Campo y ciudad, FCE/COLMEX, México, 2006, pp. 171-205. , Pensamiento educativo de Jaime Torres Bodet, SEP-Cultura/Ediciones El Caballito, México, 1985. 
-Tuñón, Enriqueta, ${ }_{i}$ Por fin . . ya podemos elegir y ser electas!, INAH/CONACUITA/Plaza y Valdés, México, 2002.

"La lucha política de la mujer mexicana por el derecho al sufragio y sus repercusiones" en Carmen Ramos Escandón (comp.), Presencia y transparencia: la mujer en la historia de México, Colmex, México, 2006, pp. 181-189.

-Tuñón, Julia, Mujeres en México, recordando una bistoria, CONACULTA/INAH, México, 2004.
-Urrutia, Elena (coord.), Estudios sobre las mujeres y las relaciones de género en México: aportes desde diversas disciplinas, COLMEX, México, 2002.

Fuentes videográficas

-Krauze, Enrique (prod.) y Luis Lupone (real.), Manuel Avila Camacho, video documental, México siglo XX: los sexenios, vol. IX, Editorial Clío, México, 1998. 